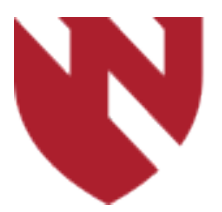

September 2020

\title{
The Impact of "Meds to Beds" on Postpartum Opioid Use
}

\author{
Kelsie Cabrera \\ University of Nebraska Medical Center \\ Anna Gorman \\ University of Nebraska Medical Center \\ Joshua Dahlke \\ Methodist Perinatal Center \\ Sonja Kinney \\ University of Nebraska Medical Center \\ Harlan Sayles \\ University of Nebraska Medical Center
}

Tell us how you used this information in this short survey.

Follow this and additional works at: https://digitalcommons.unmc.edu/gmerj

Part of the Higher Education Commons, and the Medicine and Health Sciences Commons

\section{Recommended Citation}

Cabrera, K., Gorman, A., Dahlke, J., Kinney, S., , Sayles, H. The Impact of "Meds to Beds" on Postpartum Opioid Use. Graduate Medical Education Research Journal. 2020 Sep 29; 2(1).

https://digitalcommons.unmc.edu/gmerj/vol2/iss1/18

This Conference Proceeding is brought to you for free and open access by DigitalCommons@UNMC. It has been accepted for inclusion in Graduate Medical Education Research Journal by an authorized editor of DigitalCommons@UNMC.For more information, please contact digitalcommons@unmc.edu. 


\section{The Impact of "Meds to Beds" on Postpartum Opioid Use}

Creative Commons License

(c) (i) ()

This work is licensed under a Creative Commons Attribution-Noncommercial-No Derivative Works 4.0 License. 


\section{Spontaneous Pneumothorax, Pneumomediastinum and Pneumorrhachis After Choking Steven D. Curry ${ }^{1}$, Eric T. Rohe ${ }^{1}$, Daniel J. Wehrmann ${ }^{1}$ \\ ${ }^{1}$ University of Nebraska Medical Center, Department of Otolaryngology}

Mentor: Daniel Wehrmann
Program: Otolaryngology

Type: Case Report

Background: Subcutaneous emphysema, pneumothorax, pneumomediastinum, and pneumorrhachis are rare complications of asthma exacerbation, airway infection, and choking episodes. Elevated airway pressure triggered by bronchospasm, cough, vomiting, or foreign body aspiration can lead to dissection of air through soft tissue planes.

Methods: Chart review was completed on one patient and the relevant published literature was reviewed.

Results: A 16-year-old male presented to the emergency department following a choking episode that occurred while eating breakfast. He self-administered the Heimlich maneuver to clear the airway obstruction, leading to neck swelling, muffled voice, and anterior left-sided epistaxis. The patient had a history of tonsillitis for about 1 week prior that was treated with three to four days of amoxicillin,
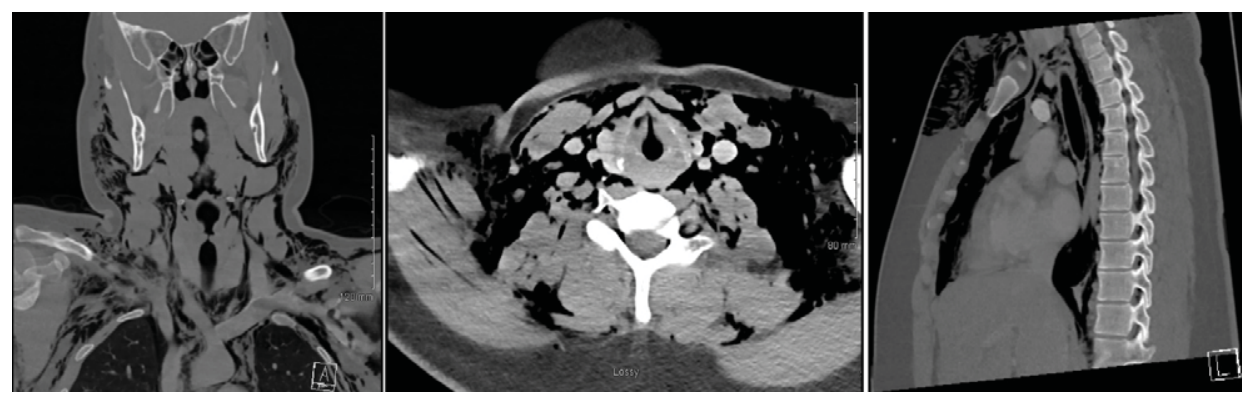

Figure 1. Coronal, axial, and sagittal CT images at the level of the glottis.

but was otherwise healthy, on no regular medications, and had no surgical history. On physical exam, the patient had bilateral neck swelling, decreased neck range of motion, cervicofacial and anterior chest crepitus, and a slightly muffled voice. The patient had unlabored breathing and no shortness of breath. Imaging with contrasted CT showed extensive free air in the neck and chest with small pneumothoraces, pneumomediastinum, and pneumorrhachis (Figure 1). The patient was admitted for observation and subsequently discharged the next day after an uneventful hospitalization.

\section{The Impact of "Meds to Beds" on Postpartum Opioid Use}

Kelsie Cabrera', Anna Gorman', Joshua Dahlke ${ }^{2}$, Sonja Kinney', Harlan Sayles ${ }^{3}$

${ }^{1}$ University of Nebraska Medical Center, Department Department of Obstetrics and Gynecology

${ }^{2}$ Methodist Perinatal Center, Omaha, NE

${ }^{3}$ University of Nebraska Medical Center, College of Public Health, Department of Biostatistics

Mentor: Joshua Dahlke

Program: Obstetrics and Gynecology

Type: Original Research

Background: To determine if there is a difference between opioid prescriptions filled before and after the implementation of "Meds to Beds" in women undergoing cesarean delivery (CD) and to assess maternal, pregnancy and labor characteristics associated with filling opioid prescriptions.

Methods: This is a retrospective cohort of women who underwent cesarean delivery from March 1, 2015 to December 31, 2015 and June 1, 2016 to December 31, 2016 at a single tertiary care center. Women were included if $\mathrm{CD}$ was performed at our center and received an opioid prescription within 6 days postpartum. By using chart review and pharmacy data, women that opted into "Meds to Beds" were identified. Discharge pharmacies were contacted to verify if opioids were dispensed in the pre-implementation group. The proportion of women who filled the opioid prescription before and after the implementation of "Meds to Beds" were then compared.

Results: 484 patient charts were reviewed for eligibility. After exclusions due to delivery at outside hospital, vaginal delivery, prior opioid use or insufficient pharmacy data, 225 women were analyzed. There were no significant maternal demographic differences between groups. Women who had none or one prior CD were more likely to fill their opioid prescription compared to women who had undergone two or more CDs. A significant number of women were more likely to fill their opioid prescription after implementation of "Meds to Beds" ( $97 \%$ vs $81 \%, \mathrm{p}<0.001)$.

Conclusion: Implementation of "Meds to Beds" improved opioid fill rate among women undergoing CD. This model may provide
Conclusions: This report presents a case of a 16-year-old male with widespread dissection of air through the neck and chest after a choking episode. Inflammation from tonsillitis may have increased the risk of air dissection caused by the Heimlich maneuver. Pneumothorax and pneumomediastinum can cause life-threatening cardiopulmonary complications and should be quickly recognized.

https://doi.org/10.32873/unmc.dc.gmerj.2.1.016

a generalizable approach for peripartum opioid stewardship by optimizing postpartum prescription administration.

https://doi.org/10.32873/unmc.dc.gmerj.2.1.017 